\title{
Developing a GIS tool to assess potential damage of future floods
}

\author{
J. Eleutério ${ }^{1,2}$, D. Martinez ${ }^{1} \&$ A. Rozan ${ }^{1}$ \\ ${ }^{1}$ UMR Cemagref/ENGEES GESTE, \\ Territorial Management of Water and Environment, France \\ ${ }^{2}$ UTR Urban Hydraulics - UMR CNRS/UdS/ ENGEES Mechanical \\ Institute of Fluids and Solids, France
}

\begin{abstract}
The evaluation of potential damage of future floods is an essential part of flood management project appraisals. Analysis results reliability is an important issue when comparing flood risk reduction project scenarios. Geographic Information System (GIS) technology plays a crucial role on flood risk analyses. On one hand, the evaluation process requires data on flood hazard and on vulnerability of assets at risk, both spatial data. On the other hand, this data must be combined in order to evaluate flood risk. Even though the role of GIS is central in the evaluation process, GIS software does not offer specific tools for achieving flood damage analysis. The use of standard methods for assessing and combining different data influences accuracy and comparability of evaluation results. Few countries in the world have developed national standard methods to assess flood damage potential. The construction of GIS-based methodologies and GIS models can be the first step toward standardisation of the whole evaluation process. In this purpose, this article presents the development of a GIS tool for evaluating future flood damage potential: F.R.A. GIS tool extension, for use with ArcGIS (ESRI). It first explains how GIS technology is used in flood risk analysis procedures. Then, the tool pre- and post-functions as well as structure of the model are detailed. Finally, a brief case study is presented in order to illustrate the functionalities of the model developed in this article. The methodology described here can be used to guide analysts on the realisation or the automation of flood risk analysis using other GIS software.
\end{abstract}

Keywords: flood damage evaluation, GIS model, risk analysis, vulnerability assessment, natural hazard, decision support tool. 


\section{Introduction}

Flood risk brings different aspects together, e.g. human, social, economic and environmental (Messner and Meyer [1]). The general purpose of different risk analyses is to understand and/or measure the possible consequences associated with the occurrence of flooding in areas occupied by vulnerable systems. This article focuses on the economic aspect of the risk. The evaluation of potential damage of future floods is an essential part of flood management project appraisals, getting more importance over time (Penning-Rowsell and Green [2]), e.g. the European Water Framework Directive (EWFD) 2007/60/EC determines that flood management projects must taken into consideration cost-benefit analysis principles. The damage evaluation results reliability is an important issue when comparing flood risk reduction project scenarios, potentially influencing decision making process. Several studies have been developed to improve damage evaluation (Messner et al. [3], Penning-Rowsell et al. [4]).

Even though the role of GIS is central in the evaluation process, GIS software does not offer specific tools for achieving flood damage analysis e.g. ArcGIS system produced by Environmental Systems Research Institute (ESRI). The use of standard methods for assessing and combining different data contributes to the improvement of the methodology and influences accuracy and comparability of evaluation results. Few countries in the world have developed national standard methods to assess flood damage potential (Dutta et al. [5]). The objectives of the EWFD 2007/60/EC incite the development of national and/or international standard methods. The construction of GIS-based methodologies and GIS models is an important step toward the standardisation of the whole evaluation process (Yi et al. [6]). In this purpose, this article presents the development of a GIS tool for evaluating future flood damage potential: F.R.A. GIS tool extension, for use with ArcGIS (ESRI).

\section{GIS and flood risk analyses}

Geographic Information System (GIS) technology plays a crucial role on flood damage evaluation process. Flood damage assessment is based on different data: flood hazard data i.e. flood parameters spatial distribution, exceedence probability; and assets vulnerability data i.e. assets exposure, susceptibility to suffer damage, and damaging potential (Penning-Rowsell et al. [4]).

In a first moment, we have to assess these different datasets. Typical GIS applications include analyses of Digital Elevation Models (DEM) over which several hydrological and hydraulic analyses can be realised (Moglen and Maidment [7]). Specific tools have been developed to explore GIS spatial data processing functionalities for use as data pre- and post-processing for hydrodynamic models like Hec-RAS, Mike Flood and Hydrarive e.g. HecGeoRas (Ackerman et al. [8]) and Mike11 GIS, both developed for use within ArcGIS software; and HydraGIS for use within MapInfo GIS software. These different software items have similar functionalities. They are generally used to: prepare input data inside the GIS structure; export data according to 
requirements of hydrodynamic numerical models; and to process results issues from hydrodynamic models for generating flood hazard distribution maps. The use of these tools provides more efficiency for the analyst, reducing technical efforts and optimising the analyses in terms of analysis possibilities. Several hydrodynamic models can be used in practice to simulate floods (Stelling and Verwey [9]), but by the end of the process, GIS software or integrated interfaces are generally used to represent and analyse the results of these models. Different studies have been carried out in order to link the hydraulic/hydrologic models to GIS e.g. Renyi and Nan [10] developed linkage between HecRAS model and GIS equivalent to Hec-GeoRAS. Other studies have been carried out in order to simulate different flood characteristics through numerical schemes inside GIS software (Tsanis and Boyle [11], Dutta et al. [5]).

GIS technology is also largely used to store and analyse stake data. Several land-use datasets have been developed for different purposes and by different agents e.g. CORINE Land Cover, BD Topo from the French National Institute of Geography (IGN) and local GIS datasets. Vulnerability data refers specifically to information concerning the assets and their susceptibility to flood water. Generally, stake vulnerability data is explored in basis of land-use datasets with different levels of detail, varying from the description of units (Gilard [12], Oliveri and Santoro [13], Edlenbruch et al. [14]) to large homogeneous areas (Simpson and Human [15], Van der Veen and Logtmeijer [16], Dutta et al. [17]).

In a second part of the evaluation process, data on hazard and vulnerability must be combined in order to calculate damage potential and support flood management. GIS technology is crucial in this step once spatial data should be combined. Basic GIS functions provide the user the possibility to realise this step. However, high levels of professional skills are required to achieve them. Generally, the evaluation of flood damage relays on the use of damage-functions to represent damaging potential for assets at risk (Penning-Rowsell et al. [4]). These damage-functions relate monetary damage potential with vulnerability and hazard characteristics, which are in the evaluation process assessed by combining previous datasets. Depending on the types of damage-function, they are used to represent damage potential for homogeneous land-uses or individual elements at risk. Few models have been developed for achieving combination of spatial data and calculation of damage potential in GIS software (Yi et al. [6], Dutta et al. [17], Betts [18]). One of the challenges in research and practical fields is the development of methods and tools for achieving flood risk evaluations and generate flood risk maps, in order to support decision-making process (De Moel et al. [19], Zerger and Wealands [20]).

\section{Flood risk analysis GIS extension}

The F.R.A. GIS tool extension is a combination of GIS functions and tools developed using Visual Basic computational language and Visual Basic Applications (VBA) for use with ArcGIS system (ESRI). The tool enhances GIS classic applications with the purpose of realising flood risk analyses through the combination of data related to flood hazard and assets vulnerability. Input data 
includes flood maps and vulnerability maps in GIS layer format, and damagefunctions. The method developed to analyse flood risk places the elements or assets at risk in the centre of the evaluation so that the assets are analysed individually, following the principles of the "unit damage evaluation" method (Penning-Rowsell et al. [4]).

\subsection{Method background}

The general equations used in the model are:

$$
A_{F P}(i)=f\left(A_{E}, F_{P(x, y)}(i)\right)
$$

where $A_{F P}$ is the intensity of flood parameters inside/over each asset for specific flood annual exceedence probability (i); $A_{E}$ is the exposure of the asset represented by its location $(\mathrm{x}, \mathrm{y}, \mathrm{z})$ during the flood event; $\mathrm{F}_{\mathrm{P}(\mathrm{x}, \mathrm{y})}$ is the maximum intensity of flood parameter(s) for a given flood event with specific (i).

$$
A_{D P}(i)=f\left(A_{F P}(i), A_{S S D}, A_{D P}\right)
$$

where $A_{D P}(i)$ is the asset damage potential related to a specific flood annual exceedence probability (i); $A_{S S D}$ is the asset susceptibility to suffer damage; $A_{D P}$ is the asset damaging potential represented by damage-functions.

$$
A_{E A D}=\int_{0}^{1} A_{D P}(i) \times i
$$

where $A_{E A D}$ is the asset expected annual damage (or average annual cost) caused by floods. The EAD value is the assets damage potential average considering flood events with annual exceedence probability varying from 0 to 1 .

\subsection{General structure and interface}

The algorithm of the tool is composed of independent functions and modules: pre-processing functions; flooding potential module; damage potential module; expected annual damage module; and post-processing functions (Fig. 1).

The model general equations; eqns. (1), (2) and (3) are individually solved using the different tool modules. The resolution of these equations depends of the datasets and parameters defined by the user. The pre-processing functions facilitate the import of input data in the model. Other equation variables as well as solution hypotheses can be entered by the user through the tool interface in ArcMAP platteform (Fig. 1).

The interface of the model consists of a toolbar composed of different menus and shortcuts that allow the user to access windows with the pre- and postprocessing functions, the model parameters and the model execution setup (Fig. 2). 


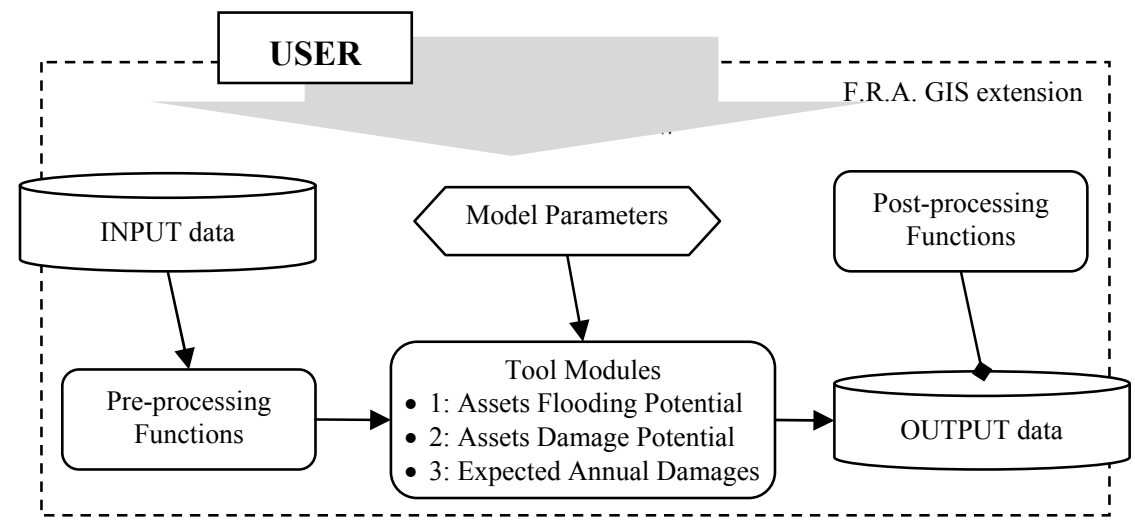

Figure 1: Tool structure.

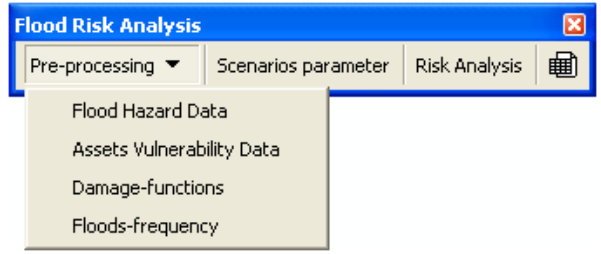

Figure 2: Model interface toolbar.

This organisation provides flexibility in the analysis procedure. Input datasets are entered in the model individually and the different calculation modules can be executed together or individually.

\subsection{Input data and pre-processing functions}

Data input requirements vary for the different evaluation modules. Basic data input requirement includes: - For assets flooding potential module: assets vulnerability maps (vector data) including at least spatial localisation of assets $(\mathrm{x}, \mathrm{y}, \mathrm{z}$ coordinates, where $\mathrm{z}$ is the relative position in relation to the digital elevation model used to construct flood maps); flood hazard maps (raster or vectors formats) including at least water-depth spatial distribution ( $\mathrm{x}, \mathrm{y}$ coordinates); - For assets potential damage module: previous datasets; assets vulnerability characteristics including at least vulnerability index (expressing asset susceptibility to suffer damages); damage-functions for the different vulnerability indexes; - For expected annual damage module: previous datasets including at least three hazard maps for events with different return periods; information concerning return periods and first damaging flood return periods.

Additional data such as other flood parameters, e.g. flow velocity, duration of submersion, or vulnerability parameters influencing damages, e.g. assets value, assets surface, can be also incorporated in the analysis. 
The tool pre-processing functions allow the user to easily process input data in order to respond to format requirements of the model. Another functionality of the pre-processing functions is that unit transformations and layer conversions can be realised without modifying the original data (new layers are generated for data processing). One example of pre-processing function interface is displayed in figure 3.

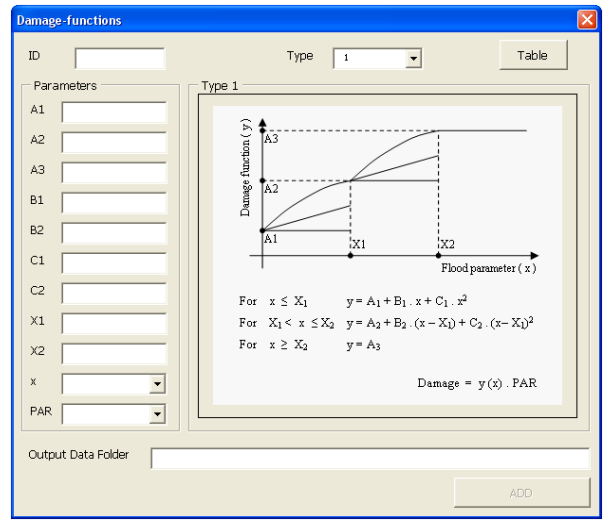

Figure 3: $\quad$ Pre-processing interface for damage-functions.

This interface is used to add damage-functions in the model project. A table containing all the variables for the different damage-functions entered is generated and stored in the project output data folder.

\subsection{Model parameters and execution options}

Before running the model, the user must specify the characteristics of the scenario(s) of evaluation. The model parameters interface (Fig. 4, left) provides the user the possibility to enter the number of scenarios as well as the characteristics of the assets layers and flood layers which will be used in the model.

When pressing the button ADD the architecture of the analysis is generated and the different input layers are added to the model project. Finally the model execution setup must be realised in order to specify which modules will be executed and to define all hypotheses for solving the model basic equations eqns. (1), (2) and (3) related to the different modules (Fig. 1). The model execution interface is used for this purpose (Fig. 4, right).

The asset layers are individually analysed. All scenarios can be analysed simultaneously or individually as well as the different modules, according to user specifications. The users can also choose to change the standard module parameters in order to adapt the model to their input data and study site characteristics. When choosing to calculate expected annual damages, the user must enter the return period of the first event for which damage occurs in the study site. The other parameters are explained in next session. 

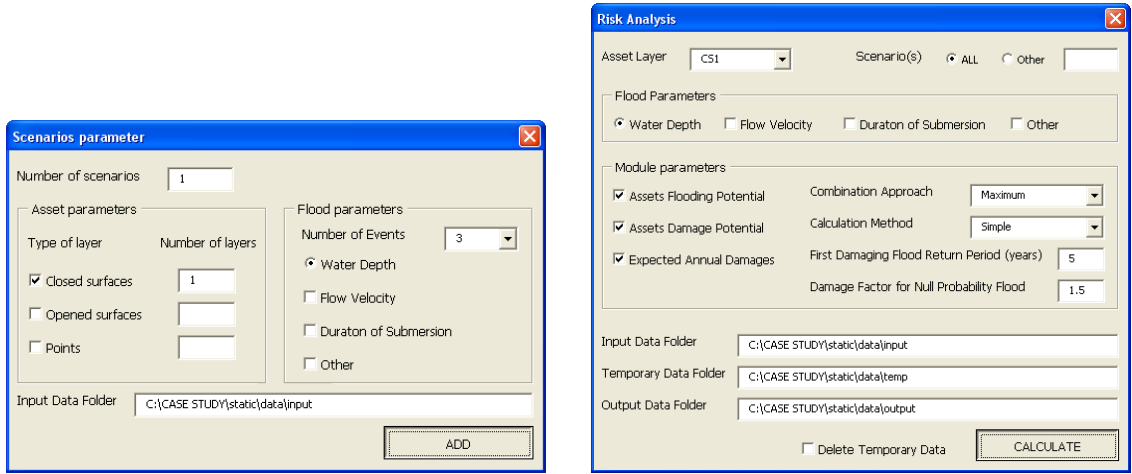

Figure 4: Model parameters interface (left) and model execution interface (right).

\subsection{Running the model and solving the basic equations}

The scheme (Fig. 5) displays how input datasets are processed to solve the model basic equations eqns. (1), (2) and (3) according to the 3 different modules respectively: 1) Assets Flooding Potential; 2) Assets Damage Potential; and 3) Expected Annual Damages.

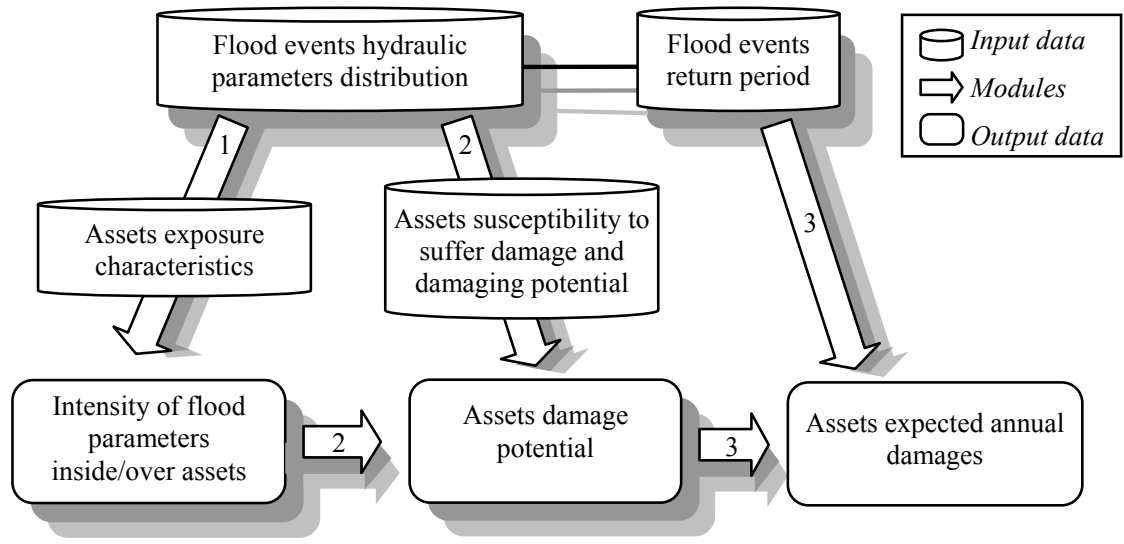

Figure 5: Tool resolution scheme.

The first module solves eqn. (1) through the combination of flood parameters with assets exposure characteristics (Fig. 5). The model routine combines GIS functions (layers over-position and table jointures) in order to import information from flood hazard layers to the assets layer, taking into account the spatial localisation of the elements at risk. The coordinates ( $x$ and y coordinates) of both are combined and water-depth is subtracted by the elevation ( $\mathrm{z}$ coordinate) of the asset in order to determine the water depth inside/over the elements at risk. The model interface (Fig. 4, right) provides to the user the possibility to choose between different approaches to combine data. 
The second module solves eqn. (2) through the application of damagefunctions (representing assets damaging potential). The asset susceptibility to suffer damages is represented by a vulnerability index, which must correspond to the identification of an existing damage-function. The model routine links the assets to the damage-functions using table jointures. In the damage-functions, damage can be dependent or independent of characteristics of the asset. In the case damage is linked to one characteristic of the asset, e.g. proportional to asset price, the correlation must be indicated in the parameter definition, and the characteristic of the asset must be described in the assets layer. Assets damage is finally calculated using the flooding parameters inside/over the elements at risk provided by the previous module and vulnerability input data (Fig. 5). The model interface (Fig. 4, right) provides to the user the possibility to choose between different methods to calculate damages.

For solving eqn (3), at least 3 flood return periods must be used to achieve the previous calculations (Fig. 5). The module 3 solves this equation using data concerning the flood events return periods and the assets damage potential previously calculated. The equation 3 is solved by means of linear regression of the known values. Two values must be entered by the user in order to do this calculation (Fig. 4, right): first damaging event return period and damage value for the null exceedence probability flood event i.e. theoretical infinity return period event. This last information must be entered in a factor format, representing how many times the null exceedence probability damage is superior to the more elevated flood return period calculated damage.

\subsection{Output data and post-processing functions}

By running the GIS tool with appropriate input datasets, the analyst is able to: estimate intensity of flood parameters inside/over assets at risk for different flood events; estimate assets damage potential related to different flood events; calculate expected annual damages for the assets; realise and compare several scenarios of evaluation; produce flood risk maps; and analyse damage and expected annual damage spatial distribution.

All data calculation is stored in the assets layers, which allows the user to generate risk maps by means of simple GIS functions. Displaying options can also be changed by using post-processing functions. These functions were elaborated to provide quick analysis of overall damage. The computational routines also create text files containing a resume of total damage by summing up unit damage for different return period events and summing up unit expected annual damages. The global results of different scenarios can be easily compared in the context of uncertainty or cost-benefit analysis.

\section{Case study}

The case study presented here illustrates the functionality of the model. We apply the F.R.A. model to calculate buildings potential damage and estimate expected annual damages in an urban community in eastern France. 
Assets vulnerability map was generated using aerial photography observation and site survey results. This map represented: building exposure by their georeferenced contours and their ground-floor height in relation to the natural terrain; building susceptibility to suffer damage by vulnerability indexes created in function of building occupation type and construction characteristics; and building damaging potential by 17 damage-functions - 2 for residential buildings (Torterotot [21]) and 15 for public and commercial buildings (DNRM [22]).

Flooding water depth maps have been generated through simulations using the $1 \mathrm{D} / 2 \mathrm{D}$ hydrodynamic Mike Flood software. We simulated floods for 10, 30 and 100 years return period floods. The maps were generated in raster formats with pixel resolution of 20x20 meters. Figure 6 provides an overview of raw data for flood and vulnerability layers.

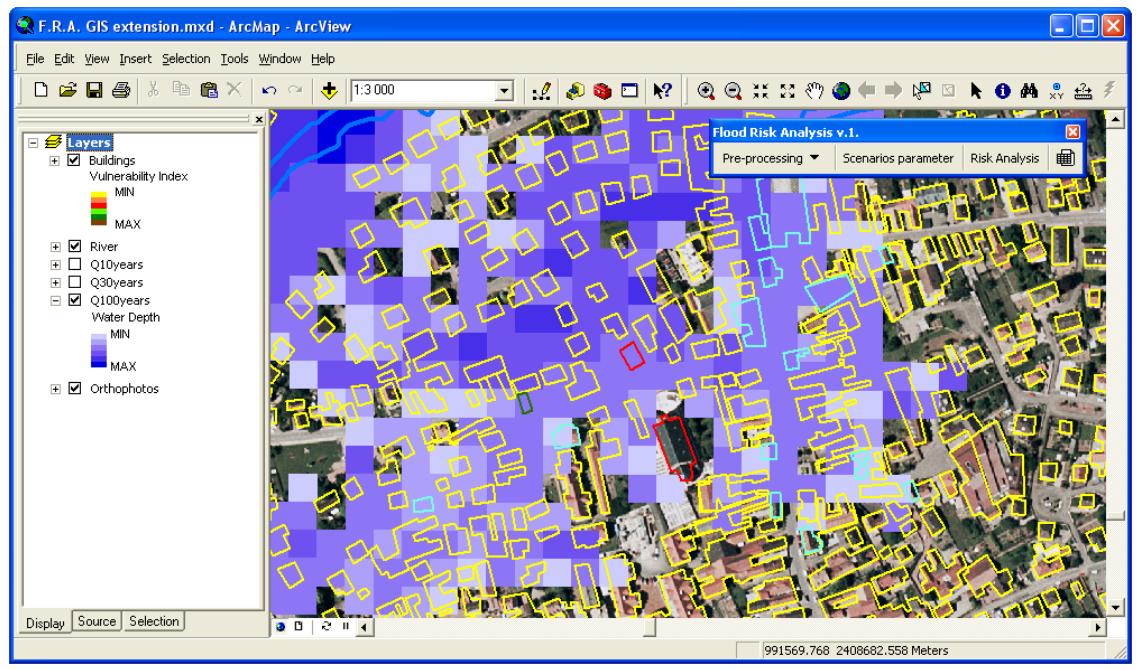

Figure 6: Case study raw data.

The 17 damage-functions were entered in the tool by means of the specific pre-processing function (Fig. 3). The ID for each damage-function corresponded to one specific asset vulnerability index. We used hazard pre-processing functions to transform the flood water depth raster layers into vector layers and to enter the information about the return period of the different flood events. Vulnerability pre-processing functions were used to create a new vulnerability layer (copying the information contained in the raw layer, changing the name of fields and the measure units, responding to the model input requirements).

Through the model parameters interface, the number of scenarios, number and type of vulnerability layers, and the number and parameters for the flood events were defined (Fig. 4, left). Closed surfaces option represents polygonal vector layers, which correspond to the building contours input data. In the model execution interface (Fig. 4, right), all modules were selected and the different required parameters entered: the maximum combination approach was used to 
estimate assets flooding potential; simple calculation method using only flood water depth parameter was used for calculating damages (the damage-functions used are dependent of only water depth parameter); 5 years return period flood was considered as first damaging flood event and asset damage for the null probability flood event was estimated 1.5 times flood damage caused by the 100 years return period flood event.

Then, the three general equations eqns. (1), (2) and (3) were solved when we executed the model, determining respectively the assets flooding potential, damage potential and expected annual damage. Figure 7 displays the graphic results for assets expected annual damage.

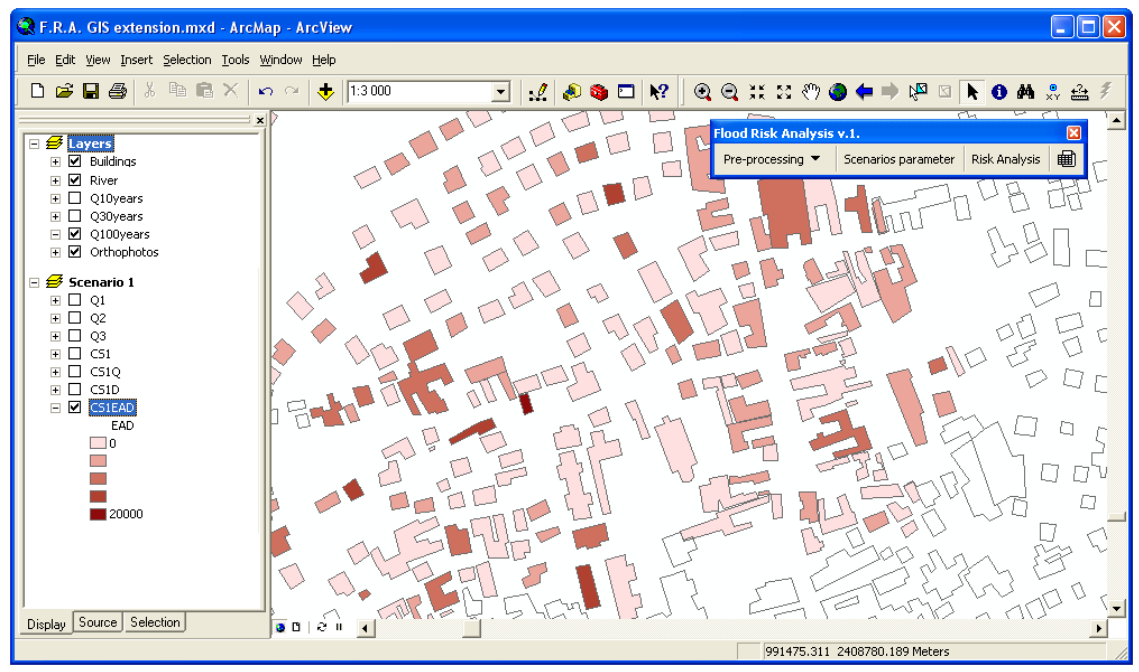

Figure 7: Case study expected annual damages.

Total expected annual damage were calculated at $350,000 €$ per year for the community evaluated. The bigger the damage is for a specific asset, the darker the colour of red in the figure above (Fig. 7). The expected average annual damage for individual assets vary from 0 (non exposed assets) to 20,000 € per year (for high vulnerable buildings in the area). Several results could be explored e.g. number of buildings impacted, distribution of damage per event return period, level of flooding water inside buildings. These simple examples of results represent some types of analysis we can easily realise using post-processing functions.

\section{Conclusions}

This article presented the development of the first version of a GIS tool for evaluating future flood damage potential: F.R.A. GIS tool extension, for use with ArcGIS 9.2. (ESRI). It explained in detail the structure of the model as well as its main functionalities including: input data pre-processing functions; assets 
flooding potential estimation module; assets damage potential estimation module; expected annual damage calculation module; and results analysis and interpretation functions. We also explained how GIS technology is used in flood risk analysis procedures. The brief case study presented here illustrated the functionalities of the model developed. The main gains enhanced by this model are: the standardisation of a general method to evaluate future floods potential damage; the generation of a friendly interface which allow the user to easily realise the analysis without depending on great background on GIS; the possibility of comparing different scenarios of evaluation in project appraisal or uncertainty analysis contexts. The utilisation of this model by stakeholders should bring great improvement on the evaluation process, and it could also provide feedback in order to improve the actual existing functionalities. The methodology described here can be used to guide analysts on the realisation or the automation of flood risk analysis using other GIS software.

\section{Acknowledgement}

The authors thank Maif Foundation for financial support of this research.

\section{References}

[1] Messner, F. and Meyer, V., Flood damage, vulnerability and risk perception - Challenges for flood damage research, Flood Risk Management: Hazards, Vulnerability and Mitigation Measures, 149-167, 2006.

[2] Penning-Rowsell, E. C. and Green, C., New Insights into the Appraisal of Flood-Alleviation Benefits: (1) Flood Damage and Flood Loss Information. J.CIWEM 14, 347-353, 2000.

[3] Messner, F., Penning-Rowsell, E., Green, C., Meyer, V., Tunstall, S. and Van der Veen, A., Evaluating flood damages: guidance and recommendations on principles and methods, FLOODsite Consortium, Wallingford, 2007.

[4] Penning-Rowsell, E., Johnson, C., Tunstall, S., Tapsell, S., Morris, J., Chatterton, J. and Green, C., The benefits of flood and coastal risk management: a manual of assessment techniques, Defra, London, 2005.

[5] Dutta, D., Herath, S. and Musiake, K., Direct Flood Damage Modeling Towards Urban Flood Risk Management, Urban Safety Enginneering, 127143, 2001.

[6] Yi, C. S., Lee, J.H. and Shim, M. P., GIS-based distributed technique for assessing economic loss from flood damage: pre-feasibility study for the Anyang Stream Basin in Korea, Nat. Hazards, 2010. DOI 10.1007/s11069010-9524-7.

[7] Moglen, G. E. and Maidment, D. R., Digital Elevation Model Analysis and Geographic Information Systems, Encyclopedia of Hydrological Sciences, John Wiley \& Sons, Ltd., 2005. 
[8] Ackerman, C.T., Thomas, A. E. And Gary, W. B., Hec-GeoRAS Linking GIS to Hydraulic Analysis Using Arc-Info and Hec-RAS, Procedings of 1999 International ESRI User Conference, Redlands, CA: ESRI, 1999.

[9] Stelling, G.S. and Verwey, A., Numerical flood simulation, Encyclopaedia of Hydrological Sciences, John Wiley \& Sons Ltd., 2005.

[10] Renyi, L. and Nan, L., Flood area and damage estimation in Zhejiang, China, Journal of Environmental Management, 66, 1-8, 2002.

[11] Tsanis, I. K. and Boyle, S., A 2D hydrodynamic/pollutant transport GIS model, Advances in Engineering Software, 32, 353-361, 2001.

[12] Gilard, O., Les bases techniques de la méthode inondabilité, Eds Cemagref, FR, 1998.

[13] Oliveri, E. and Santoro, M., Estimation of urban structural flood damages: the case study of Palermo, Urban Water, 2, 223-234, 2000.

[14] Edlenbruch, K., Germano, V., Gilbert, E., Grelot, F. and Lescoulier, C., Etude socio-économique des inondations sur le bassin versant de l'Orb, INTEREG 3 C Sud Europe - INUNDA, Cemagef, 2008.

[15] Simpson, D. M. and Human, J. R., Large-scale vulnerability assessments for natural hazards, Natural Hazards, 1573-0840, 2008.

[16] Van der Veen, A. and Logtmeijer, C., Economic Hotspots: Visualizing Vulnerability to Flooding., Natural Hazard, 36, 65-85, 2005.

[17] Dutta, D., Herath, S. and Musiake, K., A mathematical model for flood loss estimation, Journal of Hydrology, 277, 24-49, 2003.

[18] Betts H., Flood damage analysis using GIS at Gold Coast City Council, Australian Journal of Emergency Management, 33-37, 2002.

[19] De Moel H., Van Alphen J. and Aerts J. C. J., Flood maps in Europe methods, availability and use, Natural Hazards and Earth System Sciences, 9, 289-301, 2009.

[20] Zerger A. and Wealands S., Beyond Modelling: Linking Models with GIS for Flood Risk Management, Natural Hazards, 33: 191-208, 2004.

[21] Torterotot, J.-P., Le coût des dommages dus aux inondations: Estimation et analyse des incertitudes, Cereve, Ecole Nationale des Ponts et Chaussées, Paris, FR, 1993.

[22] DNRM, Guidance on the assessment of tangible flood damages, Department of Natural Resources and Mines, Brisbane, Australia, 2002. 